\title{
MAXIMUM OXYGEN CONSUMPTION RATE AND DIHYDROGENATED ERGOT ALKALOIDS IN HUMANS
}

\author{
T. INGEMANN-HANSEN, MD and J. HALKJAER-KRISTENSEN, MD \\ Laboratory for Clinical Physiology of Exercise, Department of Rheumatology and Physical Medicine \\ Rigshospitalet 2001, DK-2100 Copenhagen, Denmark
}

\begin{abstract}
The relationship of maximal oxygen uptake $\left(\mathrm{VO}_{2} \max \right)$ with dihydrogenated ergot alkaloids was investigated in twelve young men. They were subjected to graded bicycle exercise with work loads corresponding to $75 \%$ and $120 \%$ of the load necessary to elicit $\mathrm{VO}_{2}$ max. The exercise tests were performed after intravenous administration of 2 mg dihydroergostin (DE-145) as well as after saline as control, both preparations were given double-blind. $\mathrm{VO}_{2}$ max averaged (SD) $3.36(0.41) \mathrm{l} / \mathrm{min}$ and no significant difference was disclosed between the DE-145 and the control situation. Normal relationships were observed between $\mathrm{VO}_{2}$ and work load, ventilation, heart rate, cardiac output, central venous pressure and acid-base data, and these relations were unaffected by DE-145 administration. Nausea was constantly seen in all subjects tested with DE-145. It is concluded, that the present dose of DE-145 has no influence on the functional capacity of the oxygen transporting system in sedentary young men.
\end{abstract}

\section{INTRODUCTION}

Ergot alkaloids are widely used in the treatment of migraine. The pharmacological effects of these drugs on resting subjects have been investigated in numerous studies (Mellander and Nordenfelt, 1970; Ulrich and Siggaard-Andersen, 1971), whereas investigations performed during muscular work are few. The purpose of the present study was to investigate the influence of an ergot alkaloid (dihydro-ergostine) upon the maximal oxygen uptake $\left(\mathrm{VO}_{2} \quad \max \right)$ and to follow some metabolic and circulatory variables during graded bicycle exercise in young sedentary men.

\section{MATERIAL AND METHODS}

Twelve healthy men participated in this study after informed consent. The mean values (range) for age, body weight and height were 22.4 years $(20-31), 74 \mathrm{~kg}(61$. 93) and $1.82 \mathrm{~m}$. (1.75-1.92), respectively.

Oxygen uptake $\left(\mathrm{VO}_{2}\right)$ was determined with the Douglas bag technique. The expired volume was measured in a balanced Collins spirometer with $150 \mathrm{I}$ capacity. The $\mathrm{O}_{2}$ and $\mathrm{CO}_{2}$ content of the expired gas were analysed by paramagnetic (Servomex OA 189) and infrared (Capnograph Godard 146) electronic analyses, respectively (Ingemann-Hansen and Halkjaer-Kristensen, 1977). Calibration gases for these instruments were analysed on a micro-Scholander apparatus. During the experiment blood samples were drawn from a clean dry ear lobe for analyses of base excess (BE), standard$\mathrm{HCO}_{3}, \mathrm{SAO}_{2}, \mathrm{PaCO}_{2}$ and $\mathrm{pH}$ (Siggaard-Andersen, 1974). Heart rate (HR) was monitored continuously by ECG. The arterial blood pressure was measured indirectly by registration of the Korotkoff sounds.

The bicycle work was performed on a Krogh ergo- meter with the subject placed in the normal sitting position directly over the pedals. A pedal frequency of $60 \mathrm{rpm}$ was applied.

The cardiac output (Q) was measured by means of a $\mathrm{CO}_{2}$-rebreathing technique as previously described by Klausen (1965) with some modification (Klausen et al, 1968): In the rest experiments of the mean alveolar $\mathrm{CO}_{2}$ pressure $\left(\mathrm{PACO}_{2}\right)$ was assumed to be equal to mean end tidal expired air determined by the capnograph. Before the rebreathing the Grollman bag was filled with pure oxygen. The $\mathrm{PCO}_{2}$ was recorded continuously during the rebreathing, and the $\mathrm{CO}_{2}$ pressure of the mixed venous blood $\left(\mathrm{PVCO}_{2}\right)$ was determined by extrapolation both from the increase of the end expiration $\mathrm{PCO}_{2}$ and from the increase of the $\mathrm{PCO}_{2}$ of the air inspired from the Grollman bag. In the work experiments $\mathbf{Q}$ was determined with the same modification, except that the $\mathrm{PACO}_{2}$ was calculated from the Bohr formula, using dead space estimated from Asmussen and Nielsen (1956).

The central venous pressure (CVP) was measured using a floating catheter (Polystan, pp $50-150 \mathrm{~cm}$ ) inserted through the right cubital vein to the superior vena cava. The catheter was kept open by periodical injections of small volumes of sterile isotonic saline containing small amounts of heparin (10.000 U/I saline). CVP was measured continuously by means of a Statham transducer (P23DE) and recorded on a linear writer (Servogor). The measurements were done against atmospheric pressure. The pressure transducer was placed at heart level: In the supine $6 \mathrm{~cm}$ under the angle of Ludwig and in the erect position at the insertion of the 4. rib to sternum. 
At the start of the test situation either dihydroergostine (DE-145 Sandoz) (Ulrich and SiggaardAndersen, 1971) $2 \mathrm{mg}$ or placebo (0.9 per cent saline) were given intravenously in the arm. The two preparations were given in a randomised sequence, and neither the investigators nor the subjects did know which of the two preparations was given.

After the slow intravenous injection of the test substance the subject rested in a supine position for about $20 \mathrm{~min}$, then the measurements were performed (Fig. 1). Then the subject went on the bicycle ergometer, and the measurements (except blood samples) were repeated after $10 \mathrm{~min}$ in the sitting position (not indicated in Fig. 1). The graded bicycle exercise was started with a submaximal load adjusted to 75 per cent of $\mathrm{VO}_{2}$ max (measured at a preliminary visit), expired air was collected during 14-17 $\mathrm{min}$ of work and blood samples were drawn. The work was then continued on a supramaximal work load corresponding to $120 \%$ of the load necessary to elicit $\mathrm{VO}_{2}$ max. This workload led to total exhaustion within $3 \mathrm{~min}$ in every subject, averaged time 1.98 and $1.76 \mathrm{~min}$ (Range 1.00-3.00) of the control and test procedure respectively, no significant difference was demonstrated. HR just prior to exhaustion was taken as the maximal HR.

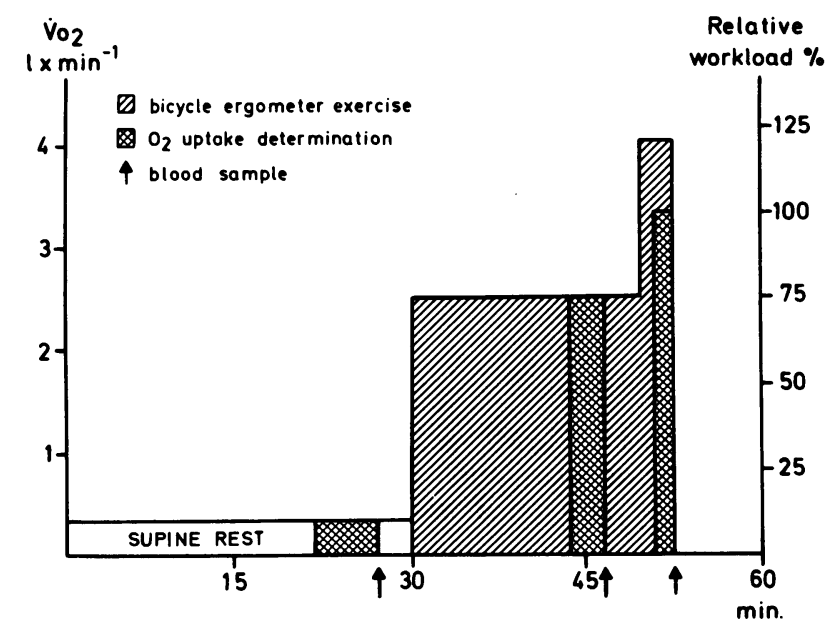

Fig. 1: The experimental protocol.

Procedure. During a preliminary visit the subject was acquainted to the test procedure including measurements of $\mathrm{VO}_{2}$ max using the 'levelling off' criterion; the two test loads 75 and $120 \%$ of $\mathrm{VO}_{2}$ max were thereafter calculated. Thereafter were the two investigations lactive and control drug) performed with at least 3 days interval.

All experiments were performed in the morning at a room temperature of $19-23^{\circ} \mathrm{C}$. On the experimental day the subjects reported to the laboratory after a light breakfast. Conventional statistical methods were used.
The significance of intra-individual differences were tested using the paired t-test.

\section{RESULTS}

The subjects responded to the graded bicycle exercise with the normal increase in $\mathrm{VO}_{2}$, no significant difference was disclosed between the results obtained after DE-145 compared with the control situation. The net efficiency averaged $23 \%$ during the submaximal work. Pulmonary ventilation $\left(V_{E}\right)$ and the ventilatory equivalent $\left(\mathrm{VE} / \mathrm{VO}_{2}\right)$ was quite appropriate to the $\mathrm{VO}_{2}$ both after i.v. administration of DE-145 and after placebo, no significant difference was revealed between these two experimental situations.

$\mathrm{VO}_{2}$ max expressed in $1 / \mathrm{min}$ averaged (SD) 3.30 (0.34) and $3.38(0.41)$ after DE-145 saline, respectively, no significant difference was demonstrated. The HR increased linearly with increased $\mathrm{VO}_{2}$ up to an average (SD) of 193 (11) and 191 (9) beats/min during the two experimental situations, respectively (Fig. 2).

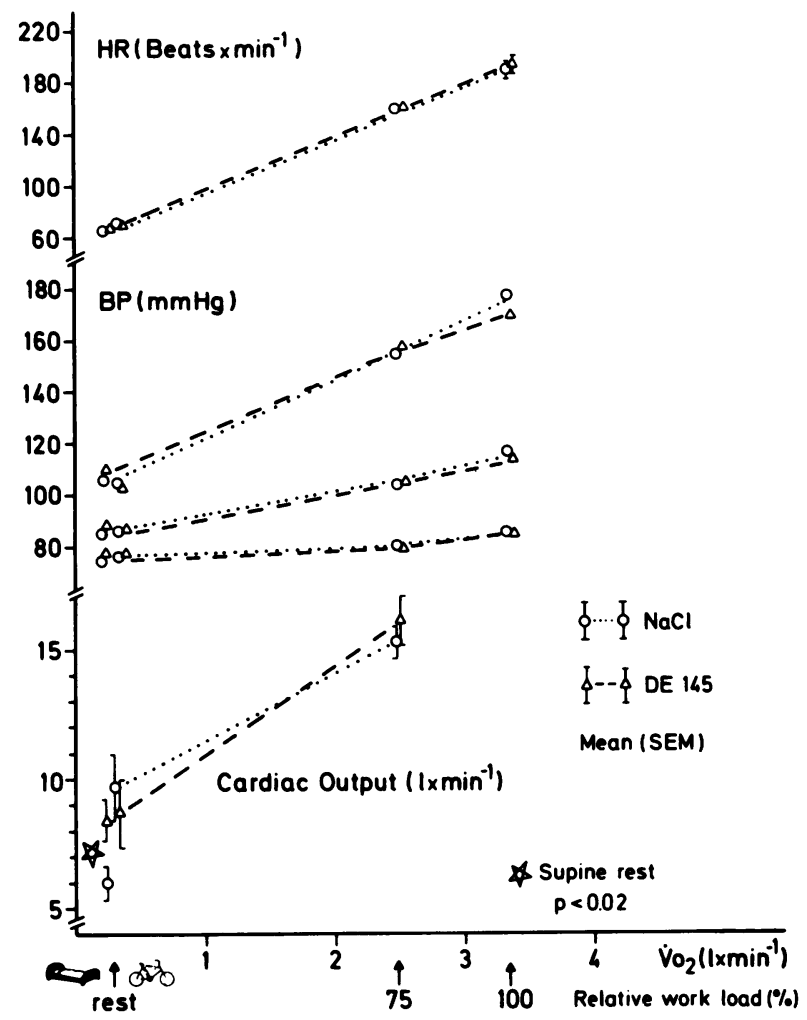

Fig. 2: The relationship for heart rate (HR), blood pressure (BP) including systolic, diastolic as well as mean $B P$, and cardiac output to oxygen uptake. $\triangle$ represents 0 the DE-145 stimulation and $\circ$ the values obtained in the $\mathbb{\Phi}$ control situation. is indicates $p<0.02$ for the cardiac $\stackrel{\mathbb{D}}{ }$ output in supine rest between DE-145 and control situation. 
The cardiac output averaged (SD) 16.1 (3.1) and $15.3(2.0) \mathrm{I} / \mathrm{min}$ for the DE-145 and control situations at the submaximal work load and the corresponding $\mathrm{VO}_{2}$ averaged (SD) $2.56(0.40)$ and $2.52(0.40)$ $\mathrm{I} / \mathrm{min}$, respectively. With increasing work loads there was a rise in the blood pressure, no significant differences were observed between the two situations (Fig. 2).

The central venous pressure decreased from the supine position to the erect position on the bicycle (Fig. 3): after DE-145 administration a significant $(P<$ 0.05) higher level was observed in the supine position, but not in the sitting position (Fig. 3). With increased work load a slightly increased level in CVP was observed, and this increase was unaffected of the two test situations. The difference between the resting and the maximal values in the control situation reached a significant level $(t=2.85, p<0.02)$.

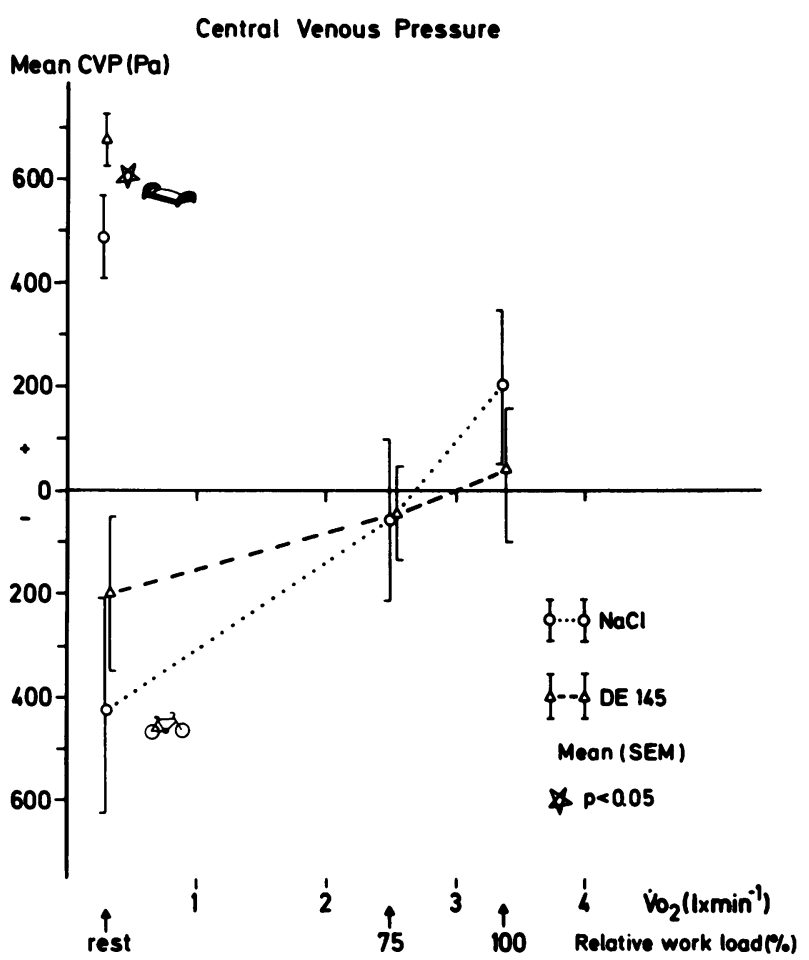

Fig. 3: Central venous pressure (CVP) against oxygen uptake. In the resting supine position CVP was elevated after DE-145 (P < 0.05). No differences between the two situations were found in the sitting position, with increased work load, however CVP in the control situation $(O)$ was significantly higher $(p<0.02)$ during maximal work compared to rest.

The arterial blood acid-base data changed with increasing work intensity, no differences being disclosed between the two experimental situations, all values are therefore included in Fig. 4, and the results were inside normal limits (1).

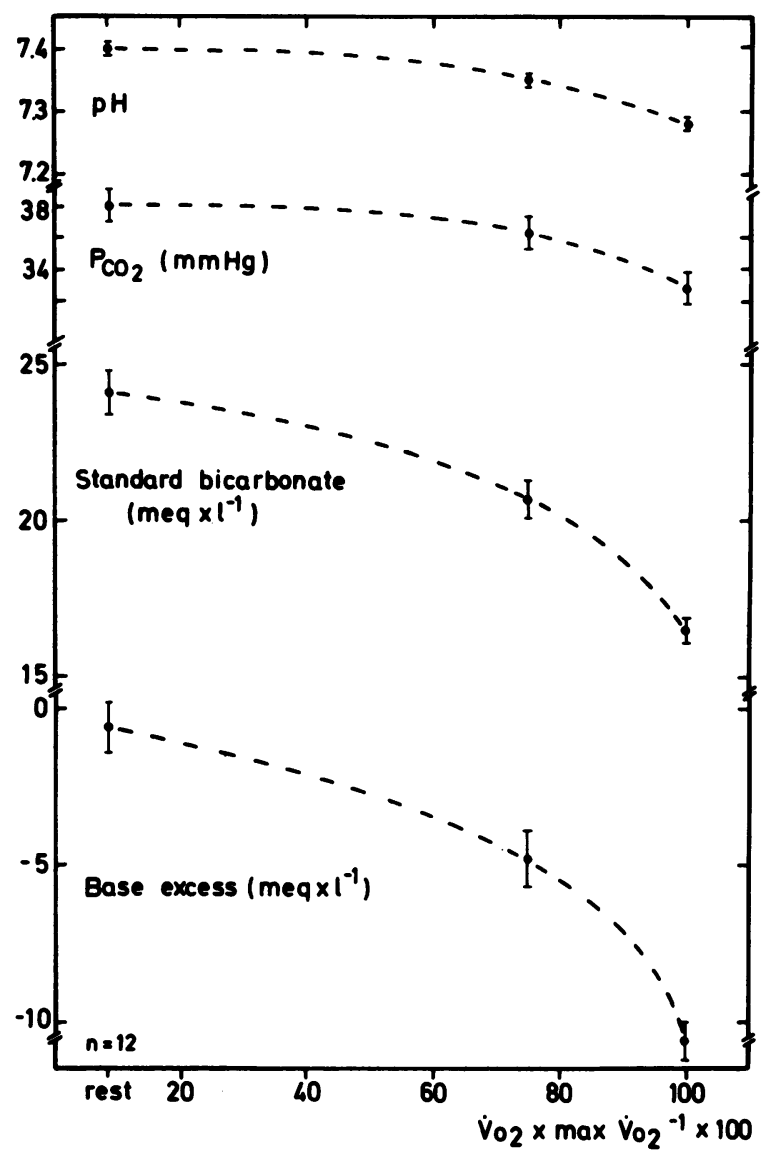

Fig. 4: Mean (SEM) acid-base data in arterialised capillary blood in relation to relative work load. Both experimental situations are included as no difference was found.

Resting conditions. The comparison between the two resting positions revealed the sitting position elicited a significantly $(p<0.01)$ higher $\mathrm{VO}_{2} \quad(1 / \mathrm{min}) \quad(0.336$ (SD 0.040)) than in the supine position $(0.283(0.037))$. no differences between the DE-145 and placebo were observed. The CVP was significantly elevated in the supine position after DE-145 administration (Fig. 3), which also was revealed for the cardiac output (Fig. 2).

Side-effects. Nausea was constantly seen in all subjects tested with DE-145, and in two cases vomiting was present, however, the experiments had not to be discontinued, and all performed the work experiments. 


\section{DISCUSSION}

The results of the present study demonstrate that dihydrogenated ergot alkaloids in the given dose have no influence on the functional capacity of the oxygen transporting system as the $\mathrm{VO}_{2}$ max was unaffected of DE-145 vs control stimulation. The CVP was significantly elevated in the resting supine position after DE-145, but not in the resting erect position neither during work. The elevation of the resting supine CVP after DE-145 is in accordance with Mellander and Nordenfelt (1970) as they found a constrictor effect of dihydro- rgotamine (DHE) mainly confined to the capacitance vessels. The CVP demonstrated a small but significant increase with increased work level (Fig. 3). This is in accordance with previous study in humans (Holmgren, 1956) indicating that the dimensions of the central circulation allow an increase of the cardiac output with an almost unaltered blood distribution. There was no difference demonstrated in the CVP during work between DE-145 and the control experiments.

Acid-base data (Fig. 4) demonstrated a normal relation to work intensity (Åstrand and Rodahl, 1977) and no differences being disclosed between the two experimental situations. Thus no influence on the muscle metabolism during work of ergot alkaloids is indicated.
When the dihydrogenated ergot alkaloids constrict के the capacitance vessels in the supine resting position a 3 redistribution of blood may occur thus increasing the $\stackrel{\mathbb{Q}}{\circ}$ cardiac filling volume thus increasing the cardiac output, which is in accordance with the present study and other $\stackrel{9}{?}$ (Mellander and Nordenfelt, 1970). However, in the $\bar{c}$ working man these effects seem to be eliminated as no differences between the two examinations were observed $\frac{\omega}{\vec{D}}$ in the present study. It seems that the pharmacological $\stackrel{\mathbb{2}}{\mathbb{2}}$ effects on the capacitance vessels of dihydrogenated $\nRightarrow$ ergot alkaloids are suppressed or dominated of other $\vec{O}$ stimuli during muscular work.

The present study indicates that dihydrogenated ergot alkaloids administered in a dose given, have no $\frac{O}{6}$ ergogenic effects (i.e. no effect on the $\mathrm{VO}_{2} \max$ ), and $\exists$ these drugs should therefore not be regarded as doping, $\vec{\infty}$ using the 'doping definition' (Williams, 1974), during iv sports events. This may have some practical implica- $\partial$ tions as ergot alkaloids are widely used drugs in the mi- o graine treatment, a common clinical condition found in an estimated $5 \%$ of the general population (Nickerson and Collier, 1975).

\section{ACKNOWLEDGEMENTS}

This study was supported by grants from the Danish National Association against Rheumatic Diseases and the Danish Council for Sports Research.

\section{REFERENCES}

Åstrand, P.-O. and Rodahl, K., 1977. Textbook of Work Physiology. McGraw-Hill Book Company, New York.

Asmussen, E. and Nielsen, M., 1956 “Physiological dead space and alveolar gas pressures at rest and during muscular exercise". Acta Physiol.Scand. 38: 1-21.

Holmgren, A., 1956 “Circulatory changes during muscular work in man”. Scand.J.Clin. Lab.Invest. 8, Suppl. 24: 48-56.응.

Ingemann-Hansen, T. and Halkjaer-Kristensen, J., 1977 “Cigarette smoking and maximal oxygen consumption rate in $\bar{\Xi}$ humans". Scand.J.Clin. Lab.Invest. 37: 143-148.

Klausen, K., 1965 "Comparison of $\mathrm{CO}_{2}$ rebreathing and acetylene methods for cardiac output". J.Appl.Physiol. 20: 763-766.

Klausen, K., Rasmussen, B., Gjellerod, H., Madsen, H. and Petersen, E., 1968 “Circulation, metabolism and ventila- $\frac{D}{O}$ tion during prolonged exposure to carbon monoxide and to high altitude". Scand.J.Clin.Lab.Invest. 22, Suppl. 103: 26-38.

Mellander, S. and Nordenfelt, I., 1970 "Comparative effects of dihydro-ergotamine and noradrenaline on resistance, $N$ exchange and capacitance functions in the peripheral circulation". Clin.Sci. 39: 183-201.

Nickerson, M. and Collier, B., 1975 "Drugs inhibiting adrenergic nerves and structures innervated by them". In Goodman, L. S. and Gilman, A. (eds.). The Pharmacological Basis of Therapeutics. Macmillan Publishing Co., Inc. $\stackrel{\mathbb{D}}{-}$ New York. pp. 540-541.

Siggaard-Andersen, O., 1974. The Acid-Base Status of the Blood 4 ed., Munksgaard, Copenhagen.

Ulrich, J. and Siggaard-Andersen, J., 1971 "Vascular effects of dihydrogenated ergot alkaloids". Angiology 22: 622- $\frac{\stackrel{\odot}{\Phi}}{\mathbb{D}}$ 628.

Williams, M. H., 1974. Drugs and Athletic Performance. Charles C. Thomas, Publisher, Springfiels. 